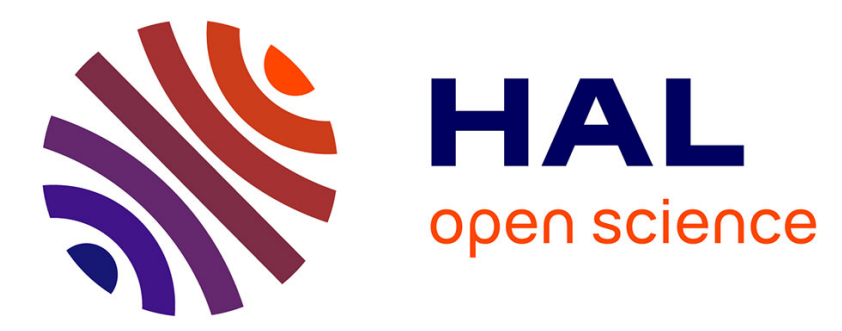

\title{
Performance of the ambient tax: does the nature of the damage matter?
}

\author{
Nasreddine Ammar, Ahmed Ennasri, Marc Willinger
}

\section{To cite this version:}

Nasreddine Ammar, Ahmed Ennasri, Marc Willinger. Performance of the ambient tax: does the nature of the damage matter?. 2011. hal-02805238

\section{HAL Id: hal-02805238 \\ https://hal.inrae.fr/hal-02805238}

Preprint submitted on 6 Jun 2020

HAL is a multi-disciplinary open access archive for the deposit and dissemination of scientific research documents, whether they are published or not. The documents may come from teaching and research institutions in France or abroad, or from public or private research centers.
L'archive ouverte pluridisciplinaire HAL, est destinée au dépôt et à la diffusion de documents scientifiques de niveau recherche, publiés ou non, émanant des établissements d'enseignement et de recherche français ou étrangers, des laboratoires publics ou privés. 


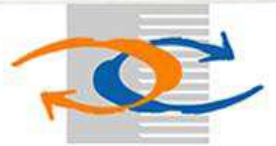

\title{
L A M E T A
}

Laboratoire Montpelliérain d'Economie Théorique et Appliquée

U M R

Unité Mixte de Recherche

«Performance of the ambient tax: does the nature of the damage matter?»

\author{
Nasreddine AMMAR \\ Ahmed ENNASRI \\ Marc WILLINGER
}

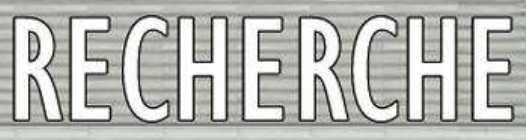

DR $n^{\circ} 2011-25$

Unite de Formation et de Recherche d'Economie Avenue Raymond DUGRAND C.S. 79606

34960 MONTPELLIER Cedex 2

Tel : 33 (0) 467158495 Fax : 33(0)467158467

E-mail : lameta@lameta.univ-montp1.fr 


\title{
Performance of the ambient tax: does the nature of the damage matter?
}

\author{
Nasreddine AMMAR* Ahmed ENNASRI $^{\dagger}$ \\ Marc WILLINGER ${ }^{\ddagger}$
}

December 10, 2011

\begin{abstract}
The ambient tax is often considered as an efficient instrument to achieve a first best outcome of ambient pollution when the regulator is less informed than the polluters. Since the ambient tax was never implemented in the field, empirical evidence is missing. Available experimental findings provide mixed evidence: efficiency is higher under external damage, i.e. if ambient pollution affects non-polluters (Spraggon, 2002, 2003) than under internal damage, i.e. if ambient pollution affects polluters themselves (Cochard et al., 2005). Since these two types of experiments relied on very different designs, it is worthwhile to compare them under a common experimental design. Our main finding is that the ambient tax is equally efficient under external damage than under internal damage.

Key-words : ambient tax, efficiency, endogenous externality, exogenous externality, experimental economics, non-point source pollution.
\end{abstract}

\section{Introduction}

When emissions are related to well-identified sources the regulator can implement traditional environmental policy instruments such as standards, emission taxes or pollution permits. Under non-point source pollution however, these policy instruments are no longer applicable and effective. While polluters know precisely their emission levels, the regulator has only limited information about individual emissions. Often he can only measure the level of ambient pollution but has no reliable measure of individual sources of emissions. Alternatively the cost of measuring or monitoring individual emissions might be prohibitive.

*LAMETA, Université Montpellier 1

†LAMETA, Université Montpellier 1

${ }_{\text {}}$ willinger@lameta.univ-montp1.fr, LAMETA, Université Montpellier 1 and Institut Universitaire de France. 
However, even if individual emissions cannot be precisely assessed, the regulator has often a clear assessment of the social cost of the ambient pollution. Therefore the optimum level of ambient pollution can still be defined, a necessary condition for designing efficient instruments to reach a socially optimum level of emissions.

One such instrument, the ambient tax/subsidy, was proposed by Segerson (1988). The ambient tax/subsidy implements a collective penalty for each potential polluter whenever the ambient pollution is beyond the target level. If ambient pollution is below the target each potential polluter receives a subsidy. More precisely each potential polluter has to pay a fine (receives a subsidy) proportional to the excess (shortfall) of ambient pollution with respect to the target level. It can be shown that whenever the marginal tax rate is equal to the marginal damage of the ambient pollution the socially optimal level of ambient pollution equals the unique Nash equilibrium of the emission game. The effectiveness of the ambient tax has been demonstrated by Segerson (1988), Shortle et al. (1998), Shortle and Horan (2001) and investigated experimentally by Spraggon (2002, 2003), Cochard et al. (2005) and Giordana and Willinger (2008). Hansen (1988) proposed an asymmetric version of the instrument, the ambient tax, for which the subsidy part is ommitted. In contast to the ambient tax/subsidy which allows for the possibility that the polluters collude in order to benefit from a subsidy the asymmetric instrument is collusion proof.

Experimental findings showed mixed evidence about the efficiency of the ambient tax/subsidy scheme proposed by Segerson (1988). While Spraggon $(2002,2003)$ found that the ambient tax/subsidy instrument is highly efficient (91.34\%), Cochard et al.'s (2005) experiment showed that the ambient tax/subsidy instrument is rather inefficient (-41.38\%) when the ambient pollution affects the polluters themselves. However they also found that an asymmetric ambient tax instrument (without the subsidy part as in Hansen, 1998) allows to reach a high level of efficiency $(80.08 \%)$ even if ambient pollution affects the polluters themselves. Still, the ambient tax instrument is much less efficient when the externality affects the polluters themselves (Cochard et al.,2005) than when the victims are disjoint from the polluters (Spraggon, 2002, 2003).

There are notable differences between these two experiments that may account for the observed divergence : group size, profit functions, strategy sets, number of rounds, etc... The most important difference between the two experiments is the existence of a strategic interaction among players before the implementation of the policy-instrument. In the experiment by Cochard et al.'s (2005) players' decisions generate a negative externality upon themselves: each polluter's decision affects both other polluters' well-being as well as his own well-being. Because of that, polluters are engaged in a strategic interaction even if no policy instrument is implemented. In contrast in Spraggon's experiment such interaction does not exist because the externality affects only agents that 
are not members of the group of polluters. The strategic interaction among players is introduced only by way of the policy instrument. In Cochard et al.'s experiment the instrument creates an additional strategic link among players. The efficiency of the ambient tax may therefore be affected by the pre-existing strategic interaction among players without any policy instrument.

We design an experiment that varies the nature of the damage - external versus internal - keeping everything else constant. Under standard behavioral hypotheses, the underlying game-theoretic model predicts that the ambient tax is equally efficient under internal than under external damage. Our main finding is that the ambient tax is equally efficient and equally reliable under both externality regimes. The remainder of the paper is organized as follows. Section 2 provides the theoretical background and section 3 describes the experimental design. In section 4 we discuss our main findings and section 5 concludes.

\section{Theoretical background}

In this section we introduce a simple model that predicts the outcome of the emission game under external and internal damage. The main objective of this model is to determine a parametric version for which we predict the same outcome under both externality regimes.

We consider $n$ identical firms producing a homogeneous product with a single input $x . x_{i}, i=1, \ldots, n$ is the amount of input used by firm $i$, with $x_{i} \geq 0$. We assume that firms are price-takers both on input and output markets. The profit of firm $i$ is a function of input use both under internal and external damage. In addition under internal damage it depends also on the level of ambient pollution, $e$ :

$\pi_{i}=\left(\begin{array}{ll}\pi_{i}\left(x_{i}\right) & \text { under external damage } \\ \pi_{i}\left(x_{i}, e\right) & \text { under internal damage }\end{array}\right)$

We assume that $\pi_{i}$ is strictly increasing and concave in $x_{i}$ and strictly decreasing in $e$. We consider the case where ambient pollution depends only on input use. Furthermore, to simplify subjects' task in the experiment we assume that individual emissions $e_{i}, i=1, \ldots, n$, are such that $e_{i}=x_{i}$,for all $i$. Finally we assume that the level of ambient pollution is equal to the sum of individual emissions, $e=\sum_{i=1}^{n} e_{i}=\sum_{i=1}^{n} x_{i}$.

The level of ambient pollution generates a damage on the economy that is measured by an external cost $c(e)$. We are interested in two particular cases : one where the damage affects only agents that are outside of the polluting sector (external damage), and one where the damage affects only agents that are inside the polluting sector, i.e. the polluting firms themselves (internal damage). We assume that $c(e)=\delta e, \delta>0$, where $\delta$ is the marginal damage from emissions.

The level of emissions chosen by firms under laissez-faire, typically differs from the socially optimum level of emissions. Under laissez-faire each firm 
chooses the level of input use that maximizes it's profit, ignoring the externality imposed on other agents. In contrast at the social optimum the level of input use by each firm should equalize the firm's marginal benefit to the marginal social cost. With our assumptions the socially optimum emission level $\left(e^{*}\right)$ is below the equilibrium level of emissions $(\widehat{e})$. We now compare the two contexts : internal and extenal damage.

\subsection{Internal damage}

\subsubsection{Ambient pollution under laissez-faire}

Let the profit of firm $i$ be defined as :

$\pi_{i}\left(x_{i}, e\right)=f\left(x_{i}\right)-c(e)=f\left(x_{i}\right)-\delta e=g\left(x_{i}\right)-\delta e_{-i}$, with $g\left(x_{i}\right)=f\left(x_{i}\right)-\delta e_{i}$.

$f\left(x_{i}\right)$ is firm $i$ 's gross profit generated by input use, while $\delta e_{i}$ is the externality cost imposed by the firm onto itself. Similarly $\delta e_{-i}$ is the externality cost imposed by other firms onto firm $i$. Given our specifications the dominant strategy for firm $i$ is to choose a level of input use that maximizes it's profit ignoring therefore the externality imposed onto it by the activity of other firms $\left(e_{-i}\right)$ and the externality imposed onto other firms by it's own activity, i.e. $(n-1) e_{i}$. The first order condition is :

$f^{\prime}\left(x_{i}\right)-\delta=0$, which gives $\widehat{x}_{i}=f^{\prime-1}(\delta)$.

Since $f^{\prime}()>0,. \widehat{x}_{i}$ is unique and concavity of $f($.$) guarantees that profit is$ maximized.

Since firms are the only agents in the economy, under internal damage social welfare $\left(W^{I}(.,).\right)$ depends solely on firms' profits. We therefore define social welfare as the aggregate profit of the polluting industry :

$$
W^{I}(x, e)=\sum_{i=1}^{n} \pi_{i}\left(x_{i}, e\right)=\sum_{i=1}^{n}\left[f\left(x_{i}\right)-\delta e\right]=\sum_{i=1}^{n} f\left(x_{i}\right)-n \delta e
$$

The optimum level of input use for each firm is defined as the level that maximizes social welfare. Taking into account the fact that $e=\sum_{i=1}^{n} x_{i}$, the first order condition is :

$f^{\prime}\left(x_{i}\right)-n \delta=0, i=1, \ldots, n$,

i.e., at the social optimum, the level of input use by each firm is such that its marginal benefit equates the marginal social cost that it generates $(n \delta)$. Since $f($.$) is strictly increasing the socially optimum level of input use for each firm is$ given by $x^{*}=f^{\prime-1}(n \delta)$. By concavity of $f(),. x^{*} \leq \widehat{x}$, leadings to an aggregate level of emissions $e^{*} \leq \widehat{e}$. Note that at the social optimum the aggregate level of input use is equal to the level of ambient pollution $e^{*}=n x^{*}$.

\subsubsection{Collusion-proof ambient tax}

In her seminal paper Segerson (1988) proposed an ambient based policy instrument that combines a fixed fine and a tax/subsidy proportional to the difference 
between the observed level of ambient pollution $e$ and an exogenously fixed target level $e^{\circ}$.

$$
T(e)=\left\{\begin{array}{c}
k+t\left(e-e^{\circ}\right) \text { if } e>e^{\circ} \\
s\left(e-e^{\circ}\right) \text { if } e \leq e^{\circ}
\end{array}\right\}
$$

where $t$ is the unit tax deducted if the level of emissions is above the target level and $s$ is a unit subsidy paid if the level of emissions is below the target. In our setting it is natural to set the target level at the socially optimum emission level : $e^{\circ}=e^{*}$. Segerson (1988) considered the case where $s=t$. However such a symmetric instrument may lead to over-abatement when the target level is the socially optimum level of pollution as in our case. Indeed firms might tacitly collude to reduce emissions below the threshold in order to be subsidized. To avoid such an issue an asymmetric instrument is required. Obviously, setting $s=0$ provides the right incentives to meet the target. We consider a collusion-

free instrument that implements the first best level of emissions $e^{*}$.

$$
T(e)=\left\{\begin{array}{c}
t(e-e *) \text { if } e>e * \\
0 \text { otherwise }
\end{array}\right\} \text {, with } t=(n-1) \delta .
$$

When the instrument $T(e)$ is implemented firm $i$ 's profit becomes :

$$
\pi_{i}\left(x_{i}, e, t\right)=\left\{\begin{array}{c}
f\left(x_{i}\right)-\delta e-t(e-e *) \text { if } e>e * \\
f\left(x_{i}\right)-\delta e \text { otherwise }
\end{array}\right\}
$$

Firm $i$ maximizes it's profit by choosing a level of input use $x_{i}$ that satisfies $f^{\prime}\left(x_{i}\right)-\delta-t=0$. The latter condition is equivalent to the first order condition for the socially optimum level of emissions whenever $t=(n-1) \delta$.

Let us now consider the case of external damage. To facilitate comparisons we adopt the same presentation.

\subsection{External damage}

\subsubsection{Ambient pollution under laissez-faire}

Under external damage the externality of the polluting sector affects only nonpolluters (for instance foreign firms or consumers) whereas polluting firms do not suffer any damage. Firm $i$ 's profit $\pi_{i}\left(x_{i}, e\right)$ is therefore not affected by $e$, the level of ambient pollution. Let us therefore rewrite firm $i$ 's profit function as $\pi_{i}\left(x_{i}, e\right)=h_{i}\left(x_{i}\right)$ with $h_{i}^{\prime}()>$.0 and $h_{i}^{\prime \prime}()<$.0 . Social damage generated by ambient pollution is now captured by a damage function $D(e)$, with $D^{\prime}()>$.0 .

Under suitable restrictions the levels of individual emissions chosen under external damage coincide with the emission levels chosen by firms under internal damage. Assume :

$$
\begin{aligned}
& D(e)=n \delta e \\
& \text { and } \\
& h_{i}\left(x_{i}\right)=g_{i}\left(x_{i}\right), i=1, \ldots, n,
\end{aligned}
$$


The first condition states that the external damage is equal to the internal damage. The second condition states that the profit function under external damage is identical to the net profit function under internal damage.

Given these assumptions, the social "internal" welfare function $W^{I}(x, e)$ and the social "external" welfare function $W^{E}(x, e)$ are identical :

$$
W^{E}(x, e)=\sum_{i=1}^{n} h_{i}\left(x_{i}\right)-D(e)=\sum_{i=1}^{n}\left[g\left(x_{i}\right)-\delta e_{-i}\right]=\sum_{i=1}^{n}\left[f\left(x_{i}\right)-\delta e\right]=W^{I}(x, e)
$$

Taking into account the fact that $e=\sum_{i=1}^{n} x_{i}$, the first order condition for maximizing $W(x, e)$ is: $h_{i}^{\prime}\left(x_{i}\right)-D^{\prime}(e)=0 \Longleftrightarrow h_{i}^{\prime}\left(x_{i}\right)=n \delta$

Social welfare is maximized whenever the marginal profit of firm $i$ is equal to the marginal damage that it generates.

Under laissez-faire, each firm chooses a level of input use that maximizes it's profit. Since $h_{i}\left(x_{i}\right)=g_{i}\left(x_{i}\right)$, firm $i$ chooses the same level of input under external and under internal damage; i.e. a level of input use that does not account for the negative externality.

\subsubsection{Collusion-proof ambient tax}

As in the case of internal damage, we consider a collusion-free instrument, that is equivalent to the one introduced for the internal damage.

$$
T(e)=\left\{\begin{array}{c}
t(e-e *) \text { if } e>e * \\
0 \text { otherwise }
\end{array}\right\} \text {, with } t=(n-1) \delta .
$$

Firm $i$ 's profit when the instrument $T(e)$ is implemented becomes :

$$
h_{i}\left(x_{i}, e, t\right)=\left\{\begin{array}{c}
f\left(x_{i}\right)-\delta e-t(e-e *) \text { if } e>e * \\
f\left(x_{i}\right)-\delta e \text { otherwise }
\end{array}\right\}
$$

$f^{\prime}\left(x_{i}\right)-\delta-t=0$ which is equivalent to the first order condition for the socially optimum level of emissions whenever $t=(n-1) \delta$.

\section{Experimental design}

\subsection{Practical specifications}

In our experimental setting we chose the group size to be equal to 6 players as in Spraggon (2002). Each player can choose a level of input in the strategy space $\{0,1, \ldots, 30\}$. As we show below, given the specification of the profit function, the dominant strategy both under external and internal damage is $x_{i}=30$ for all $i$. Given the specification of the profit function the optimum level of input use is $x^{*}=20$ as shown below. 
In order to simplify the instructions we chose a quadratic profit function and a linear externality cost under internal damage :

$\pi\left(x_{i}, e\right)=f\left(x_{i}\right)-c(e)=-3 x_{i}^{2}+192 x_{i}-12 e$, with $f\left(x_{i}\right)=-3 x_{i}^{2}+192 x_{i}$

and $c(e)=12 e$. Note that with these parameters each player's profit function is increasing ${ }^{1}$ and concave in $x_{i}, g\left(x_{i}\right)=-3 x_{i}^{2}+192 x_{i}-12 x_{i}=-3 x_{i}^{2}+180 x_{i}$.

Since $e=\sum_{i=1}^{6} x_{i}$, the individual profit function can be rewritten as $\pi\left(x_{i}, e\right)=$ $-3 x_{i}^{2}+180 x_{i}-12 e_{-i}$. It can be easily checked that the equilibrium input use of firm $i$, is $x_{i}=30$. Given our specification of the profit function, the social welfare function under internal damage is given by :

$$
W^{I}(x, e)=\sum_{i=1}^{6} \pi_{i}\left(x_{i}, e\right)=\sum_{i=1}^{6}\left[-3 x_{i}^{2}+180 x_{i}\right]-60 \sum_{i=1}^{6} x_{i}
$$

It is easy to check that the optimum input use of firm $i$, is $x_{i}^{*}=20$.

Under external damage the corresponding profit function is $h\left(x_{i}\right)=2700-$ $3\left(30-x_{i}\right)^{2}$, and the welfare function :

$$
W^{E}(x, e)=\sum_{i=1}^{n} h_{i}\left(x_{i}\right)-D(e)=\sum_{i=1}^{n}\left[2700-3\left(30-x_{i}\right)^{2}\right]-60 \sum_{i=1}^{6} x_{i}
$$

\subsection{Experimental procedures}

The experiment was divided into two sequences : in sequence 1 subjects played the emission game under laissez-faire for 10 successive rounds. In sequence 2 subjects played a second series of 10 rounds with the implementation of the ambient tax. We compare two treatments : internal damage and external damage. Note that we did not control for possible order effects, i.e. effects due to the ordering of sequences 1 and 2 . The reason is that our main objective is to compare the efficiency of the ambient tax under two different externality regimes when the prevailing situation was the absence of regulation.

Subjects were recruited from a large subject pool of more than 2000 volunteers. After their arrival at the experimental lab, subjects were randomly assigned to a cubicle. In each session subjects were randomly assigned to a group of 6 players, for the whole duration of the experiment. We collected 6 independent observations per treatment. Standard procedures were implemented : anonymity, implementation of common knowledge of the instructions by public reading, understanding check, .. The experiment was fully computerized and all sessions were run under the same conditions. The average duration of a session was approximately 1 hour and 30 minutes. Participants earned an average of 22 Euros including the show up fee. Further details can be found in the written instructions (see appendix).

\footnotetext{
${ }^{1}$ In the absence of regulation, the profit function increaes up to $x_{i}=30$ and decreases for values larger than $x_{i}=30$.
} 


\subsection{Performance indicators}

As in Cochard et al. (2005) our analysis takes into account two indicators for measuring the impact of the ambient tax : efficiency and reliability. Efficiency measures how close the instrument reaches the target; reliability measures how often the instrument reaches the target.

\subsubsection{Efficiency}

We measure efficiency in two different ways. First we look at the average emission per group. The ambient tax will be considered as efficient if the average emission of each group coincides with the target emission level which is equal to 120 units with our specifications $(6 \times 20)$. In case of "laissez-faire" the predicted group average emission (Nash equilibrium) is equal to 180 units $(6 \times 30)$.

Second we rely on the improvement (alteration) of social welfare after the introduction of the ambient tax-instrument. Let us define $W^{\circ}$ and $W^{*}$ the predicted levels of welfare under laissez-faire and at the social optimum respectively. As in Spraggon (2002) we define the efficiency rate as :

$E=\frac{W-W^{\circ}}{W^{*}-W^{\circ}} \times 100$

where $W$ is the observed level of welfare. Note that $E$ varies between $0 \%$ and $100 \%$, since the worst outcome is obtained at the Nash equilibrium under laissez-faire.

\subsubsection{Reliability}

Efficiency alone is not sufficient to assess the performance of an instrument. Performance depends also on the reliability of the instrument, i.e. it's predictability: if the same instrument is implemented under similar conditions we should expect to observe the same outcome with respect to the level of efficiency. We measure reliability, by the variability of the instrument's efficiency (see Cochard et al., 2005). The instrument's variability can be captured in two different ways : i) by measuring the inter-periodic variability which reflects the variation of the average efficiency of the groups between two consecutive periods and ii) by the inter-group variability which measures the difference of the level of efficiency between groups for every period.

\subsubsection{Asymptotic values}

Using averages can sometimes be misleading, in particular because averages put the same weight on each period, neglecting the fact that subjects may learn as the game is repeated. Therefore, it is important to assess the trend in input use in order to find out whether learning drives subjects towards the target level. We therefore estimate asymptotic values using the following generic econometric model (see Noussair et al., 1995). 


$$
Z_{i t}=Z^{\infty}+Z^{0} \frac{1}{t}+\mu_{i}+\varepsilon_{i t}
$$

In the analyses that follow the independent variable $Z_{i t}$ is either the level of input use $\left(X_{i t}\right)$ or the level of efficiency $\left(E_{i t}\right) . i=1, \ldots, 6$ is the group index and $t=1, \ldots, 10$ the time index. $\mu_{i}$ is a normally distributed random variable that captures the individual random effect and $\varepsilon_{i t}$ is a standard random error term. $Z^{\infty}$ is the estimated asymptotic value of the dependent variable (when $t$ tends to infinity) and $Z^{\infty}+Z^{0}$ is the estimated value for period 1. A policy instrument is preferable if it's estimated asymptotic value gets closer to the target value than other instrument.

\section{Results}

We present our findings according to three criteria: the level of emissions, the level of welfare and reliability.

\subsection{Emissions}

We start with a general assessment of the ambient tax (result 1) before comparing the two externality regimes (result 2). We report our results first with respect to average emissions and second with respect to asymptotic emissions.

\subsubsection{Average emissions}

Result 1 : The ambient tax reduces sharply the level of emissions both under internal and under external damage.

\section{Support for result 1}

Table 1 displays the average level of group emissions for the internal and the external damage treatments, before and after implementation of the tax instrument. The average emission in the laissez-faire sequence exceeds the average emission in the ambient tax sequence for each individual group in both treatments. Therefore for both treatments the average group emission with the ambient tax is significantly lower than under laissez-faire (Wilcoxon signedrank test, two-sided, $\mathrm{p}=0.027$ for external damage and for internal damage). It is noteworthy that under laissez-faire average group emissions are lower than predicted (180 units) while in the ambient tax sequence they are above the target level (120 units). Under laissez-faire the average group emission is equal to 169 units under external damage and 170 units under internal damage, an insignificant difference (Wilcoxon-Mann-Whitney test, two-sided, $\mathrm{p}=0.8728$ ), but both are significantly lower than predicted (t-test, one-sided, $\mathrm{p}=0.000$ for both treatments). In contrast in the ambient tax sequence average group emissions are typically above the target level (120 units per group) averaging 124 under external damage and 129 under internal damage. Both levels are significantly larger than predicted for both treatments (t-test, one-sided, $\mathrm{p}=0.000$ for both treatments), in line with earlier findings (Spraggon 2002, Cochard et al., 2005). 


\section{( INSERT TABLE 1 AND FIGURE 1 ABOUT HERE)}

Result 2 : The ambient tax is equally efficient for reducing emissions under external damage than under internal damage.

Support for result 2

Average emissions are larger under internal damage (129 units) than under external damage (124 units), but the null hypothesis of equal average group emission under internal and external damage cannot be rejected (WilcoxonMann-Whitney test, two-sided, $\mathrm{p}=0.1495$ ). While the Wilcoxon Mann-Whithney test does not reject the null hypothesis, there are nevertheless some marked differences between the two treatments. Under external damage for three groups out of six the average emission levels almost hit the target level (120 units). Such outcome is never reached under internal damage. Also, figure 1 which re-

ports the evolution of the average level of group emission over time according to the type of damage, clearly shows that the average emission curve for internal damage is above the emission curve for external damage (in sequence 2 where the tax is implemented). Finally, the null hypothesis of equal distributions of group emissions is rejected for the ambient tax-sequence (Kolmogorov-Smirnov test, $\mathrm{p}=0.000$ ) but not for the laissez-faire sequence (Kolmogorov-Smirnov test, $\mathrm{p}=0.928$ ). These tests suggest that the ambient tax instrument is slightly more efficient for reaching the target emission level under external damage than under internal damage.

\subsubsection{Asymptotic emissions}

Following the econometric model outlined in sub-section 3.3.3, we estimate $X^{\infty}$ the asymptotic value of group emissions according to the model: $X_{i t}=$ $X^{\infty}+X^{0} \frac{1}{t}+\mu_{i}+\varepsilon_{i t}$. Table 2 reports the results of the model with random effects (Hausman test). In accordance with average emissions estimated asymptotic group emissions in the laissez-faire sequences are lower than predicted for both treatments. It looks as if subjects' behavior mitigates to some extent the externality problem. However the asymptotic group emission level is not significantly different from the prediction under external damage (t-test, twosided, $\mathrm{p}=0.103$ ) but is significantly lower than predicted under internal damage (t-test, one-sided, $\mathrm{p}=0.019)$. Figures $2(\mathrm{a})$ and $2(\mathrm{~b})$ report the frequency distributions of individual emissions under laissez-faire: $75 \%$ of subjects' decisions correspond to the level of emissions of 30 units under external damage and only $55 \%$ under internal damage, a non-significant difference (Kolmogorov-Smirnov test, $\mathrm{p}=0.635$ ). The difference between the average and the estimated asymptotic values stems from the fact that group emissions tend to increase over time suggesting that the level of average emission tends to converge to it's equilibrium value under laissez-faire.

(INSERT TABLE 2 ABOUT HERE) 
In the ambient tax sequence the asymptotic group emission is above the equilibrium prediction for both treatments. The null hypothesis of equal asymptotic emission levels cannot be rejected (t-test, one-sided, $\mathrm{p}=0.1044$ for external damage and $\mathrm{p}=0.8585$ for internal damage). A possible reason for the excess level of group emissions under the ambient tax regime is that some subjects anticipated wrongly that their group members would emit less than 20 units and thus decided to choose a level of individual emission larger than 20 units. The slight difference between average and asymptotic values stems from the fact that group emission was constant over time. Figures 2(c) and 2(d) show that only $35 \%$ of subjects' decisions correspond to 20 units of emission under external damage and $51 \%$ under internal damage, a non-significant difference (Kolmogorov-Smirnov test, $\mathrm{p}=0.968$ ).

(INSERT FIGURE 2 ABOUT HERE)

\subsection{Welfare}

As for emissions, we measure the efficiency of the ambient tax under both regimes by relating to average and asymptotic measures of welfare.

\subsubsection{Average efficiency}

Result 3 : The efficiency rate of the ambient tax does not significantly differ between external and internal damage.

Support for result 3

Figure 3 shows the evolution of the efficiency rates over time according to the type of damage. In the laissez-faire sequence the efficiency rate under internal damage is above the efficiency rate under internal damage. No such difference is apparent in the ambient tax sequence.

\section{(INSERT FIGURE 3 ABOUT HERE)}

Table 3 reports the efficiency rates for each group before and after the implementation of the ambient tax, for internal and external damage. Asymptotic efficiency rates (estimated as described in section 4.2.2) are also reported in the table. The average efficiency rate with the ambient tax is larger than without for all groups and for both treatments (Wilcoxon signed-rank test, two-sided, $p=0.028$ for external damage and for internal damage). The null hypothesis of equal average efficiency rates for internal and external damage cannot be rejected for both sequences (Wilcoxon-Mann-Whitney test, two-sided, $\mathrm{p}=0.631$ for the laissez-faire sequence and $\mathrm{p}=0.521$ for the ambient tax sequence).

The average efficiency rates under laissez-faire are low (12.04\% under external damage and $\mathbf{1 7 . 6 5 \%}$ under internal damage) but significantly larger than 
the predicted rate $(0 \%)$ (t-test, one-sided, $\mathrm{p}=0.015$ for external damage and $\mathrm{p}=0.017$ for internal damage). In contrast, the average efficiency rate with the ambient tax $(85.65 \%$ under external damage and $84.40 \%$ under internal damage) is significantly lower than the prediction (100\%) for both treatments (t-test, one-sided, $\mathrm{p}=0.038$ for external damage and $\mathrm{p}=0.011$ for internal damage).

(INSERT TABLE 3 ABOUT HERE)

An additional analysis of the impact of the ambient tax on the efficiency rate is captured by the following regression $E_{i t}=\theta+\delta D+\rho S+v_{i}+\varphi_{i t}$, where

$E_{i t}$ is the efficiency rate of group $i$ in period $t . D=1$ for external damage (and 0 otherwise). $S=0$ in periods where the tax is implemented. $v_{i}$ and $\varphi_{i t}$ are random variables capturing idiosyncratic group effects and random effects, respectively. Table 4 reports the results of random effects model. As expected the effect of the ambient tax sequence is negative and significant. The tax increases significantly the efficiency rate by about $70 \%$. The type of damage has no effect on the efficiency rate. We therefore conclude that the efficiency rate of the ambient tax does not depend on the type of damage according to our experimental results.

\section{(INSERT TABLE 4 ABOUT HERE)}

\subsubsection{Asymptotic efficiency}

We estimate asymptotic efficiency based on the model introduced in subsection 3.3.3: $E_{i t}=E^{\infty}+E^{0} \frac{1}{t}+\mu_{i}+\varepsilon_{i t}$. Table 5 describes the results of a random effects model (Hausman test). Under laissez-faire the asymptotic efficiency is low for both types of damages: about $11 \%$ for external damage and $15 \%$ for internal damage, but significantly higher than $0 \%$ in both treatments (t-test, $\mathrm{p}=0.008$ for external damage and $\mathrm{p}=0.021$ for internal damage).

After the implementation of the ambient tax asymptotic asymptotic efficiency improved significantly, reaching levels above $84 \%$ for both types of externalities. The null hypothesis of equal asymptotic efficiency for both regimes cannot be rejected (see table 6). However these values are significantly lower than $100 \%$ - the optimal efficiency level - for both treatments (t-test, one-sided, $\mathrm{p}=0.018$ for external damage and $\mathrm{p}=0.001$ for internal damage).

(INSERT TABLE 5 ABOUT HERE)

\section{(INSERT TABLE 6 ABOUT HERE)}

\subsection{Reliability}

We now turn to our final assessment by measuring the performance variability both in absolute (emission variability) and relative terms (efficiency variability). 
Result 4 : There is no significant difference of reliability of the instrument between internal and external damage.

Support of result 4

We provide support for result 4 in terms of emission variability and efficiency variability.

\subsubsection{Emission variability}

Average emission variability Table 7 shows that the inter-periodic variability of average group emission ${ }^{2}$ is equal to $2.38 \%$ under internal damage and $3.31 \%$ under external damage before the ambient tax is implemented, an insignificant difference (Wilcoxon-Mann-Whitney test, two-sided, $\mathrm{p}=0.631$ ). After implementation of the tax the average inter-periodic variability is equal to $2.31 \%$ and $2.16 \%$ for external and internal damage respectively, an insignificant difference (Wilcoxon-Mann-Whitney test, two-sided, $\mathrm{p}=0.262$ ). Furthermore, the Inter-periodic variability is not significantly different between the two sequences and for both treatments (Wilcoxon signed-rank test, two-sided, $\mathrm{p}=$ 0.600 for external damage and $\mathrm{p}=0.345$ for internal damage).

(INSERT TABLE 7 ABOUT HERE)

Figure 4 reports the inter-group variability of average emissions ${ }^{3}$ which is equal to $5.7 \%$ under internal damage and $5.9 \%$ under external damage before the application of the tax, an insignificant difference (Wilcoxon-Mann-Whitney test, two-sided, $\mathrm{p}=0.969)$. After the implementation of the tax the average intergroup variability is equal to $7.16 \%$ and $6.51 \%$ for external and internal damage respectively, an insignificant difference as well (Wilcoxon-Mann-Whitney test, two-sided, $\mathrm{p}=0.969$ ). The Inter-group variability is not significantly different between sequences for both treatments (Wilcoxon signed-rank test, two-sided, $\mathrm{p}=0.092$ for external damage and $\mathrm{p}=0.386$ for internal damage). We therefore conclude that reliability, as measured by emission variability is equal under both ambient tax regimes.

(INSERT FIGURE 4 ABOUT HERE)

Asymptotic emission variability Table 8 reports estimates of asymptotic inter-period reliability indicators. Inter-periodic reliability in group i between periods $\mathrm{t}$ and $\mathrm{t}-1$ is calculated by the absolute variation of efficiency between these two periods: $\left|\Delta E_{i t}\right|=\left|E_{i t}-E_{i t-1}\right|$. Before the implementation of the tax the estimated asymptotic inter-periodic variability is $62 \%$ under internal damage

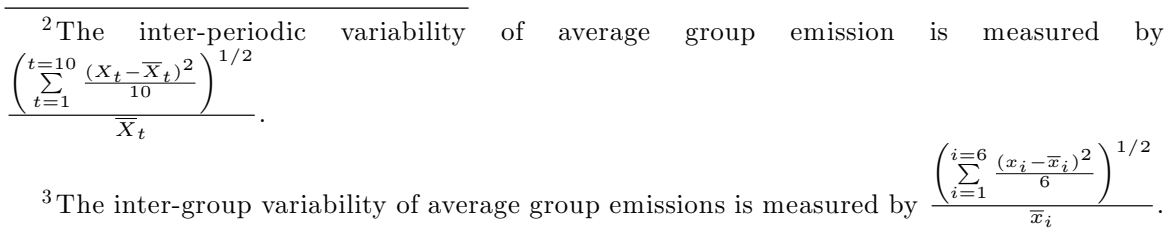


and $-0.7 \%$ under external damage, a significant difference (t-test, $\mathrm{p}=0.002$ ). After the implementation of the tax, the asymptotic values are close together, and the difference is no longer significant (t-test, $\mathrm{p}=0.986$ ) confirming our result about average emission.

(INSERT TABLE 8 ABOUT HERE)

\subsubsection{Efficiency variability}

Average efficiency variability The ambient tax reduces sharply the variability of the average efficiency: from $22.80 \%$ to $3.58 \%$ in the case of external damage, and from $32.16 \%$ to $7.56 \%$ in the case of internal damage (see table 9 ). While the efficiency gain is larger in the case of internal damage, the instrument's reliability does not differ significantly between the two treatments (Wilcoxon-Mann-Whitney test, one-sided, $\mathrm{p}=0.423$ ).

Although the difference is not significant, there seems to be faster convergence under external damage towards the socially optimum level of emissions. The strategic interaction among players under internal damage might have favoured opportunistic behavior preventing coordination on the efficient outcome.

(INSERT TABLE 9 ABOUT HERE)

Asymptotic efficiency variability Table 10 present the estimation of as-

ymptotic inter-group reliability indicators. Inter-group reliability is calculated by the standard deviation between groups in period t: $S G_{t}=S G^{\infty}+S G^{0} \frac{1}{t}+\varepsilon_{t}$ where $\mathrm{t}$ denote time $(\mathrm{t}=1, \ldots, 10), \varepsilon_{t}$ is an error term that follows an $\operatorname{AR}(1)$ process $\varepsilon_{t}=\rho \varepsilon_{t-1}+\lambda_{t}$, where $\lambda_{t}$ is an i.i.d. residual component.

As for the asymptotic emission variability, the instrument leads to a strong reduction of variability in efficiency both under external and internal damage. There is an insignificant difference between the two types of externalities (see table 11).

(INSERT TABLE 10 and TABLE 11 ABOUT HERE)

\section{Conclusion}

The experiment reported in this paper was intended to compare the efficiency and the reliability of the ambient tax in two radically different contexts : one where polluters do not bear any cost for their emissions and one where the polluting firms generate a negative externality onto each other. These two contexts are radically different because, depending on the context, interacting players may - or not - take into account their impact on others.Our experimental findings shows that the ambient tax is equally efficient and reliable in both context. This is an important result, since the ambient tax is often considered as an optimal instrument for ambient pollution. Our results provide strong experimental 
support to this conjecture. Of course more evidence is required, in particular experimental field data. However given the results our artefactual lab experiment, we conjecture that similar qualitative results will be obtained in a framed field experiment.

\section{References}

[1] Cochard, F., Willinger, M., Xepapadeas, A. (2005), "Efficiency of Nonpoint Source Pollution Instruments: An Experimental Study", Environmental and Resource Economics, 30, 393-422.

[2] Cochard, F., Ziegelmeyer, A., Boun My, K. (2007), "Regulation of Nonpoint Emissions under Limited Information: A Stress Test of the Ambient Tax Mechanism", Journal of Environmental Economics and Management, Forthcoming.

[3] Giordana, G., Willinger, M. (2008), "Regulatory instruments for monitoring ambient pollution", Handbook of Environmental Experimental Economics, J. List \& M. Price (eds), Forthcoming.

[4] Hansen, L. G. (1998), "A Damage Based Tax Mechanism for Regulation of Non-Point Emissions", Environmental and Resource Economics, 12, 99112 .

[5] Horan, R., Shortle, J., Abler, D. (1998) "Ambient Taxes when Polluters have Multiple Choices", Journal of Environmental Economics and Management, 36, 186-99.

[6] Kreps, D., Milgrom, P., Roberts, J., Wilson, R. (1982), "Rational Cooperation in the Finitely Repeated Prisoner's Dilemma", Journal of Economic Theory, 27, 245-252.

[7] Ledyard, J. O. (1995), "Public Goods: A Survey of Experimental Research", in J. Kagel and A. Roth, eds. Handbook of Experimental Economics, 111-194.

[8] Noussair, C., Plott, C. R., Riezman, R. G. (1995); "An Experimental Investigation of the Patterns of International Trade", American Economic Review, 86, 462-491.

[9] Segerson, K. (1988), "Uncertainty and Incentives for Nonpoint Pollution Control", Journal of Environmental Economics and Management, 15, 8798.

[10] Shortle, J., Horan, R., Abler, D.G. (1998), "Research Issues in Nonpoint Pollution Control", Environmental and Resource Economics, 11, 571-85. 
[11] Shortle, J., Horan, R. (2001), "The Economics of Nonpoint Pollution Control", Journal of Economic Surveys, 15, 255-89.

[12] Spraggon, J. (2002), "Exogenous Targeting Instruments as a Solution to Group Moral Hazards", Journal of Public Economics, 84, 427-456.

[13] Spraggon, J. (2004a), "Individual Decision Making in a Negative Externality Experiment", Experimental Economics, 7, 249-269.

[14] Spraggon, J. (2004b), "Testing Ambient Pollution Instruments with Heterogeneous Agents", Journal of Environmental Economics and Management, $48,837-856$. 


\title{
Documents de Recherche parus en $2011^{1}$
}

\author{
DR n²011 - 01 : Solenn LEPLAY, Sophie THOYER \\ «Synergy effects of international policy instruments to reduce \\ deforestation: a cross-country panel data analysis » \\ DR n²011 - 02 : Solenn LEPLAY, Jonah BUSCH, Philippe DELACOTE, Sophie \\ THOYER \\ « Implementation of national and international REDD \\ mechanism under alternative payments for environemtal \\ services: theory and illustration from Sumatra » \\ DR n²011 - 03: Stéphanie AULONG, Robert KAST \\ «A conceptual framework to assess vulnerability. Application to \\ global change stressors on South Indian farmers » \\ DR n²011 - 04 : Nicolas QUEROU, Raphael SOUBEYRAN \\ « Voting Rules in Bargaining with Costly Persistent Recognition » \\ DR n²011 - 05 : Pierre COURTOIS, Rabia NESSAH, Tarik TAZDAÏT \\ «How to play the games? Nash versus Berge behavior rules» \\ DR n²011-06: Pierre COURTOIS, Tarik TAZDAÏT \\ « Learning to trust strangers: an evolutionary perspective » \\ DR n²011 - 07 : Pierre COURTOIS, Tarik TAZDAÏT \\ « Bargaining over a climate deal: is it worse to wait and see? » \\ DR n²011 - 08 : Mathieu COUTTENIER, Raphael SOUBEYRAN \\ « Diplomatic Intervention in Civil War: Trade for All or Trade for \\ One?»
}

DR n²011 - 09: Edmond BARANES, Jean-Christophe POUDOU

«Internet access and investment incentives for broadband service providers »

DR n²011 - 10: Sadek MELHEM, Michel TERRAZA, Mohamed CHIKHI

«Cyclical Mackey Glass Model for Oil Bull Seasonal »

\footnotetext{
${ }^{1}$ La liste intégrale des Documents de Travail du LAMETA parus depuis 1997 est disponible sur le site internet : http://www.lameta.univ-montp1.fr
} 
DR n²011 - 11: Marianne LEFEBVRE, Sophie THOYER, Mabel TIDBALL, Marc WILLINGER

«Sharing rules for a Common-Pool Resource with private alternatives »

DR n²011 - 12: $\quad$ Ahmed ENNASRI, Marc WILLINGER

« Managerial incentives under competitive pressure: Experimental investigation »

DR n²011 - 13: Sadek MELHEM, Abdul Salam DIALLO, Michel TERRAZA

« Hypothesis of Currency Basket Pricing of Crude Oil: An Iranian Perspective »

DR n²011 - 14 : Marianne LEFEBVRE, Lata GANGADHARAN, Sophie THOYER

«Do Security-differentiated Water Rights Improve Efficiency? »

DR n²011 - 15: Antoine BERETTI, Charles FIGUIERES, Gilles GROLLEAU « Using Money to Motivate Both 'Saints' and 'Sinners' : A Field Experiment On Motivational Crowding-Out»

DR n²011-16: Jérémy CELSE

«Damaging the Perfect Image of Athletes: How Sport Promotes Envy»

DR n²011 - 17: Charles FIGUIERES, Estelle MIDLER

«Deforestation as an externality problem to be solved efficiently and fairly »

DR n²011 - 18: Rachida HENNANI, Michel TERRAZA

«Etude de la performance d'une Value-at-Risk chaotique pour l'indice CAC 40 »

DR n²011 - 19: Charles N. NOUSSAIR, Marc WILLINGER

«Mixed strategies in an unprofitable game: an experiment »

DR n²011 - 20 : Mohamed ALI BCHIR, Anne ROZAN, Marc WILLINGER

«Does higher trust lead to higher performance? An experimental investigation »

DR n²011-21: Sophie CLOT, Gilles GROLLEAU, Lisette IBANEZ

«Do Good Deeds Make Bad People ?»

DR n²011- 22: Marianne LEFEBVRE

«Sharing Rules for Common-Pool Resources when Self-insurance is Available : an Experiment» 
DR n²011 - 23: $\quad$ Valérie CLEMENT, Alain MARCIANO

«Welfarism, Libertarian Paternalism and Political Economy: Three Perspectives on Economic Expertise »

DR n²011-24: Jean Michel SALLES

«Valuing Biodiversity and Ecosystem Services: Why Linking

Economic Values with Nature? »

DR n²011 - 25: Nasreddine AMMAR, Ahmed ENNASRI, Marc WILLINGER

"Performance of the ambient tax: does the nature of the damage matter?» 
Contact :

Stéphane MUSSARD : mussard@lameta.univ-montp1.fr 


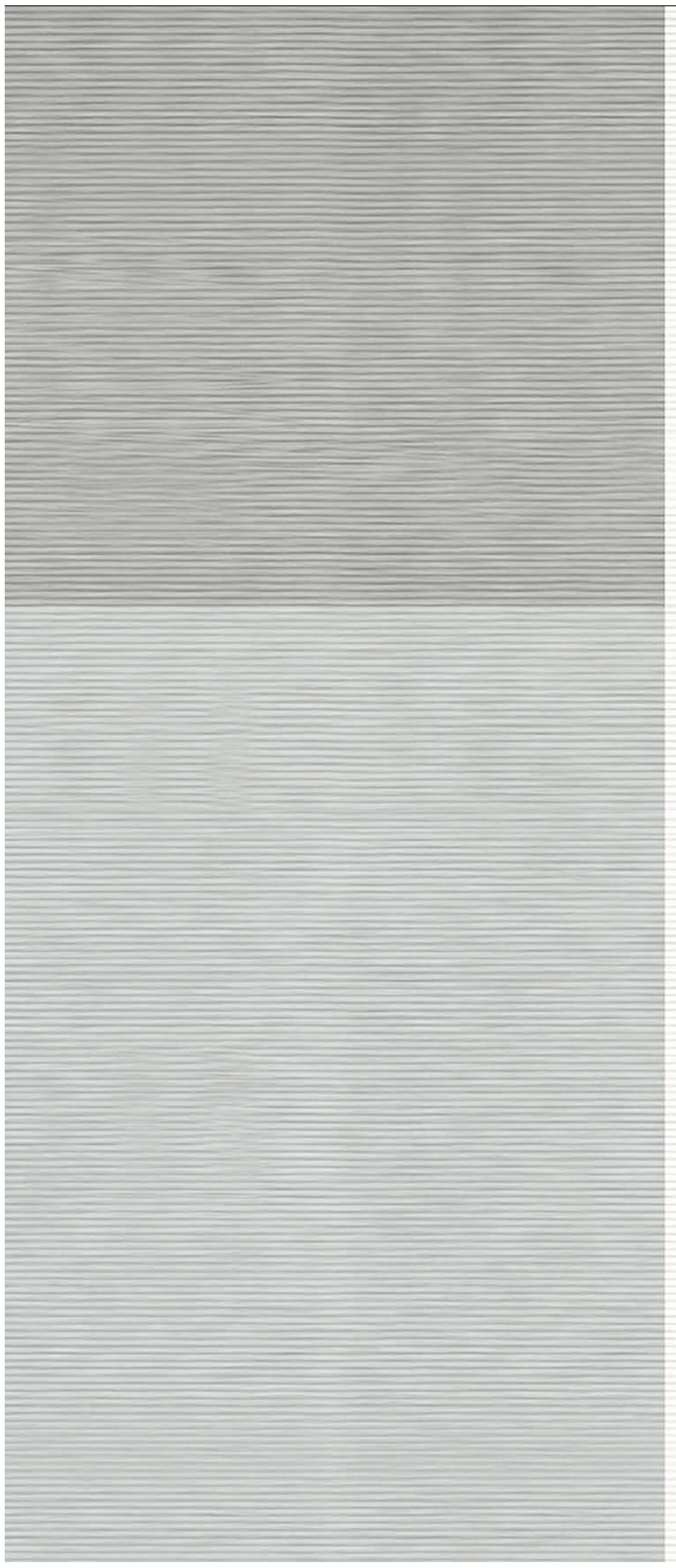

